\title{
Research on the Current Situation and Promotion Strategies of the Education of Cultural Self-confidence of International School Students in China
}

\begin{abstract}
Yuxiao Wang ${ }^{1}$
${ }^{1}$ Huisheng International School, Shenzhen, Guangdong, China

*Corresponding author. Email: yuxiao.wang@hs-college.com

ABSTRACT

Youth is not only as an important force to promote historical development and social progress, but also to be a key subject to strengthen cultural self-confidence. The degree of recognition of national culture and the depth of cultural self-confidence foundation of youth directly affect their depth of viewing cultural differences, which affect their value system in the collision with the world's multiculture in the future as well. Combined with the current situation of International School Students' cultural self-confidence education, this study analyzes the dilemma of International School Students' cultural self-confidence, and puts forward the strategies of strengthening the cooperation between family, school and community, and jointly carrying out cultural self-confidence education, so as to provide reference for improving the comprehensive quality of International school students.
\end{abstract}

Keywords: International School, Youth, Cultural self-confidence, Promotion improvement

\section{INTRODUCTION}

Economic globalization is the inevitable trend of historical development, which accompanied by the impact of multiculture and values. In the wave of economic globalization, the inheritance of Chinese national culture has encountered unprecedented challenges. Cultural self-confidence is a nation's full affirmation of its own cultural value[1]. The rapid rise of China, a super-civilization-type country, has continued 5,000 years of civilization without interruption, which means that in the era of economic globalization, the fate of China has been closely related to the fate of the whole world, and its influence on the world will increase as it grows stronger. Professor Zhang Weiwei, a well-known Chinese political scholar and dean of China Research Institute of Fudan University, said: The rise of a country must be accompanied by the rise of its own discourse power, otherwise it may lead to failure[2]. The construction of youth's cultural self-confidence needs to be taken seriously by schools, families and society, the construction of youth's cultural self-confidence needs the attention of schools, families and society, and it is necessary to guide them to observe and comment on their own country and the outside world with their own sights and words, so that these young people who could not only "telling a good story of China" , but also could have conversation with the world on the international stage in the future[3]. Therefore, it is urgent to carry out the education of Chinese students' cultural self-confidence in international schools, cultivate teenagers' cultural consciousness and improve their cultural identity.

\subsection{Development Status of International Schools in China}

The development of economic globalization has led to the internationalization of education, international schools in China have experienced rapid growth in the past decade[4]. With the development of China's comprehensive national status, the development scale and running level of international schools in different periods have roughly experienced three stages: 1) The initial stage of development in the 1980s and 1990s was mainly to settle the matter of children of expatriates working in China continuing to receive education[5]. 2) During the accelerated development stage from the 1990 s to the end of the last century, the increasing number of children of expatriates has not only greatly increased the number of international schools in various 
cities, but also rapidly expanded the scale of school running[6]. 3) From the beginning of this century to the present, with the rapid development of China's economy, the national income level has been continuously improved, with views and values in more and more families have changed, applying for foreign universities has become another popular choice for them. Under this situation, international education of public schools and private international schools sprang up sharply. According to the "China's International School Development Report (2019)": Between 2010 and 2019, the number of international schools had doubled, reaching 821 . Over 513 thousand students are currently studying in international schools, with an average of 392 students per school; From 2016 to 2018, the annual growth rate of the number of international schools in Chinese mainland exceeded $10 \%$, especially in 2018 , it increased by 87 schools a year, achieving an increase of nearly $12 \%$, setting the highest growth rate in history[7].

As one of the implementers of international education, international schools undoubtedly shoulder the mission of cultivating international talents[8]. In the international schools where multiculturalism gathers, how to maintain the national culture and the independence of education and how to improve Chinese students' recognition of their traditional culture is essential. Thus, international schools need to face up to the existence of multiculturalism while build up cultural confidence to achieve common development on the basis of respecting multiculturalism[9].

\subsection{Characteristics of students in international schools}

Teenagers in adolescence have great tolerance and acceptance for the foreign culture, as well as the epochmaking and innovative culture. They have the ability to learn new technologies quickly, who also are willing to use new technologies to reproduce and disseminate these new cultures and knowledge. But meanwhile, lack of experience of life and society, especially their values have not been fully established with the limitations to the scope of cognition of foreign culture, it is easy for teenagers to have a blind sense of identity and worship[10]. Furthermore, in order to ensure the "dominant position" of international curriculum, international schools oriented to further studies constantly compress and weaken local curriculum, and students rarely have the opportunity to learn local courses systematically and continuously such as Chinese geography, Chinese history and politics[11]. Therefore, under the impact of multiple values and the lack of traditional culture education, the young people in international schools can only understand Chinese traditional culture on a piecemeal level, which makes them extremely lack of national identity and recognition of national culture.

\section{PRESENT SITUATION OF CULTURAL SELF-CONFIDENCE OF THE STUDENTS IN INTERNATIONAL SCHOOL}

In order to make up for this deficiency, many international schools established a series of traditional culture education courses to enhance Chinese students' awareness of national identity, and then enhance their cultural self-confidence[12]. In this study, 31 Chinese students $(90 \%$ are senior high school students, $10 \%$ are junior high school students and primary school students) and 31 Chinese teachers of international schools in Shenzhen were investigated by questionnaires, meanwhile, some of them were also interviewed. A total of 62 questionnaires were distributed and 62 questionnaires were recovered (including 31 questionnaires distributed by students and 31 questionnaires distributed by teachers), with an effective rate of $100 \%$. Through the analysis of the results of this questionnaire survey, the following conclusions are drawn:

\subsection{The influence of mass media on the quality of teenagers' acquisition of traditional cultural knowledge}

The popularity of the Internet has greatly changed the way for young people to acquire knowledge and enriched the channels for young people to understand Chinese excellent traditions. As a product of the Internet age, the number of young users has increased dramatically due to its high timeliness and strong interactivity[13]. It can be seen from the survey results that $90.32 \%$ of young people use new media as a way to understand Chinese traditional culture, and more than $75 \%$ use traditional media (radio, television, etc.), which is also an important way to acquire knowledge.

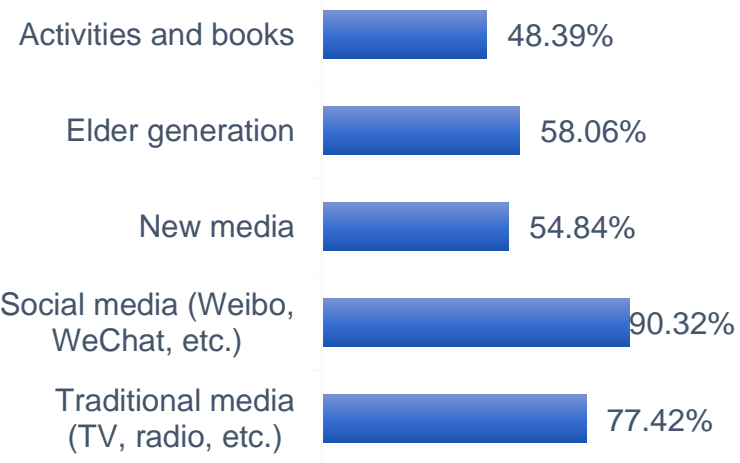

$0.0020 .00 \% 200 \% 2.0182 .0000 .00 \%$

Figure 1 Ways of the interviewed students understand Chinese traditional culture

With the vigorous development of China's media industry, many TV programs have incorporated traditional cultural elements, presenting the difficult traditional culture in a lively and enjoyable form, which 
is widely favored by young people, such as "Lecture Room", "National Treasure", "Chinese Poetry Conference" and "The Readers", etc[14]. However, under the operation of commercial capital, there are some programs or articles that are inappropriate to traditional culture or distort and spoof traditional culture in order to attract attention and improve the click browsing rate. It can be seen that social media is a "double-edged sword" for growing teenagers. In the network age, it is necessary to do research on how to use healthy and positive mass media to help teenagers' build up their cultural self-confidence. Therefore, the mass media plays an extremely important and complex role in promoting the cultivation of young people's cultural self-confidence, which bears social responsibility as well[15].

\subsection{The influence of family education on teenagers' cultural self-confidence}

According to the results of the questionnaire survey, family education also plays a vital role in building teenagers' cultural confidence. More than $75 \%$ of the teenagers who participated in the survey expressed that their parents had educated them on Chinese traditional virtues, and more than $75 \%$ of their parents would take them to visit historical places of interest during the holidays to understand Chinese history; however, there are over $60 \%$ of teachers thought that the initiative and enthusiasm of family education had not been fully mobilized.

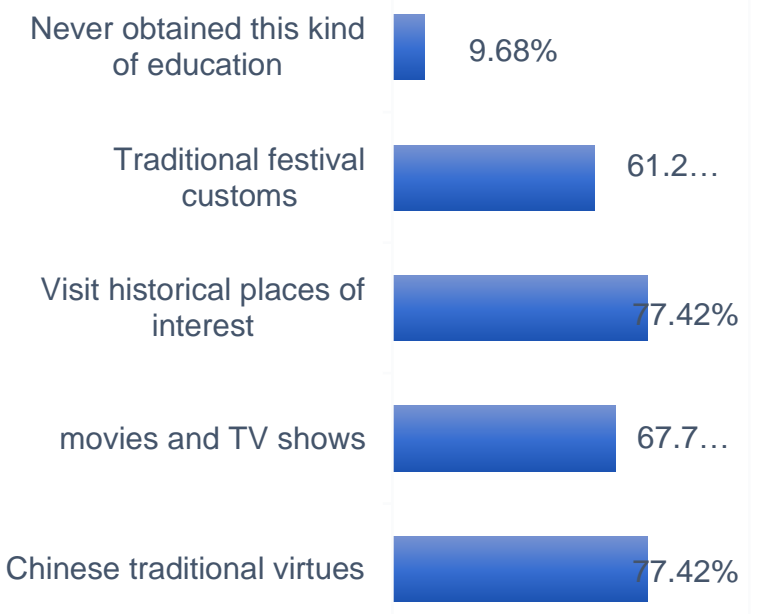

Figure 2 The traditional cultural family education methods accepted by the interviewed students

Many parents think that sending their children to school is to learn scientific knowledge. They only pay attention to the scores of the main courses, who even don't care what their children can learn in the "subclass" and whether they do well in the exam. In most parents' and children's cognition, the college entrance examination is the most important thing. (Grade 11th Chinese teacher A)
Some parents in our class have discussed with me whether we can change the Chinese traditional culture class into English class, because the children will take the TOEFL test soon. Besides, this school-based course is so special that children won't come into contact with these things after going abroad, so they don't have to spend time studying, which is a waste of time and energy. (Grade 11th class teacher B)

According to the survey data and interview information, under the pressure of going to college, parents' attention is mainly focused on their children's academic performance in the main course. The educational philosophy of many families ignores the shaping of children's spiritual level, which makes some young people have a weak sense of cultural selfconfidence. The cultural self-confidence education is considered as "secondary courses", with the subtle guidance make teenagers have lower awareness of cultural self-confidence education[16]. Furthermore, with the advent of the Internet age and the progress of science and technology, the integration of Chinese traditional culture into family education is facing unprecedented challenges. Some parents are addicted to electronic products and completely give up reading books. The lack of traditional cultural knowledge leads to their inability to educate their children about cultural self-confidence[17].

\subsection{Cultivation of Teenagers' Cultural Confidence by International School Teaching System}

From the survey data, it is not difficult to see that the four international schools where the teachers who accepted the questionnaire work generally support more than $70 \%$ of the youth's cultural self-confidence education, however, only more than $40 \%$ of schools have developed systematic teaching plans and arrangements for related courses. The survey results show that more than half of the Chinese students in these four international schools are not satisfied with the traditional culture courses, and only $30 \%$ of the students are willing to participate in activities related to traditional culture. Why is the effect of the existing cultural self-confidence education in schools not as good as expected? 


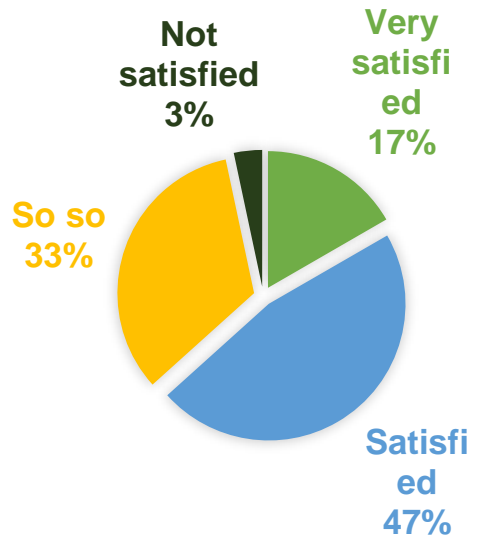

Figure 3 Satisfaction of Interviewed Students with School Traditional Culture Education

According to interviews with students, the teaching methods of traditional culture courses are single and rigid, which lack interaction with the students, only in order to simply complete the teaching tasks which make the course boring, which causes college students to lack of interest in learning. Eventually, students have passively accepted the teaching content and fail to give full play to the effectiveness of teaching[18]. Therefore, the well-intentioned traditional culture education does not resonate among these teenagers, and it seems that it cannot meet the needs of modern teenagers.

I thought this kind of course suppose to be very interesting, but the teacher's lecture in the whole class didn't even have any interaction. If there was no pressure to study credits, I would definitely not take this course. (Grade 10th student A)

Our traditional culture course is too boring. I don't understand why learning guqin, go chess and calligraphy can improve my cultural confidence. I'm going to apply for universities next year, and I don't want to spend time studying these subjects which are not very useful for further studies. (Grade 11th student B)

The pressure to apply for universities makes international schools more or less become examoriented. It is clear that, for international schools, the admission rate of students to prestigious universities is a test of the quality of international school education. Therefore, the pressure of applying for university and high-density study make teenagers lose their interest in learning and their pursuit of knowledge. Indeed, examoriented education ignores the diversification of students' individual development and the establishment of cultural self-confidence as well[19].

More than $65 \%$ of the 31 teachers who participated in the questionnaire survey were teachers in high school and middle school. Nearly $50 \%$ of them have master degree and undergraduate degree respectively. And more than half of them have overseas study background or international teamwork experience. As teachers who have experienced the collision of multiple cultures, they have a lot of personal experience in the education of cultural self-confidence. According to the survey data, more than $90 \%$ of teachers agree that it is imperative to implement traditional culture education in international school, since the excellent traditional culture contains rich national spirit and moral concept, which is an important ideological nutrient for the construction of teenager's cultural self-confidence in the new era. In particular, it plays an extremely important guiding role in educating young people in values, ideals and beliefs from the perspective of the community of human destiny[20], However, teachers' knowledge accumulation of Chinese traditional culture seem to far less than imagined, among which less than $20 \%$ have standard of "very understanding" and $74.19 \%$ are at the level of "basic understanding".

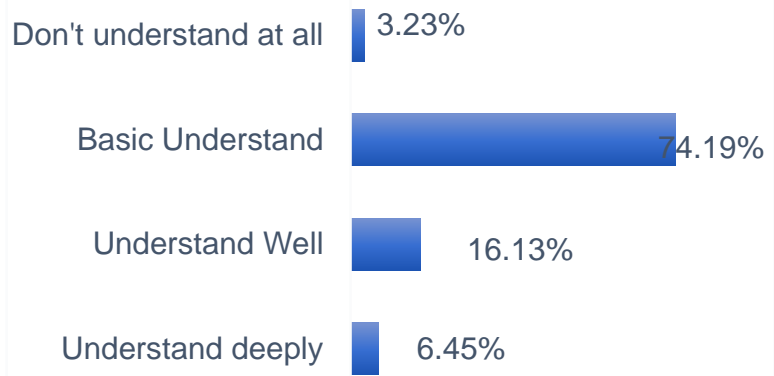

$0.00 \% 20.00 \% 0.00 \% 0.00 \% 0.00 \%$

Figure 4 The degree of understanding of traditional culture by interviewed teachers

When referring to the teaching resources of related subjects, the commonly used resources are: Chinese, geography, history textbooks, related extracurricular reading materials and network resources. Although the utilization rate of existing teaching materials is over $80 \%$, the effective utilization rate of teaching materials is not satisfactory. More than $65 \%$ of teachers show that the teaching materials are fixed, but each student's interests, characteristics, needs and abilities are often quite different. The teaching process supposes to proceed from reality, adapt to students' needs, teach students in accordance with their aptitude, and design differentiated instruction that meets students' characteristics[21], however, the lack of relevant teacher training makes the potential of teachers' secondary development of teaching materials not fully exerted, which is also one of the difficulties encountered in developing cultural self-confidence education. Therefore, making full use of existing teaching resources is also an urgent problem to be faced in developing cultural self-confidence education. 


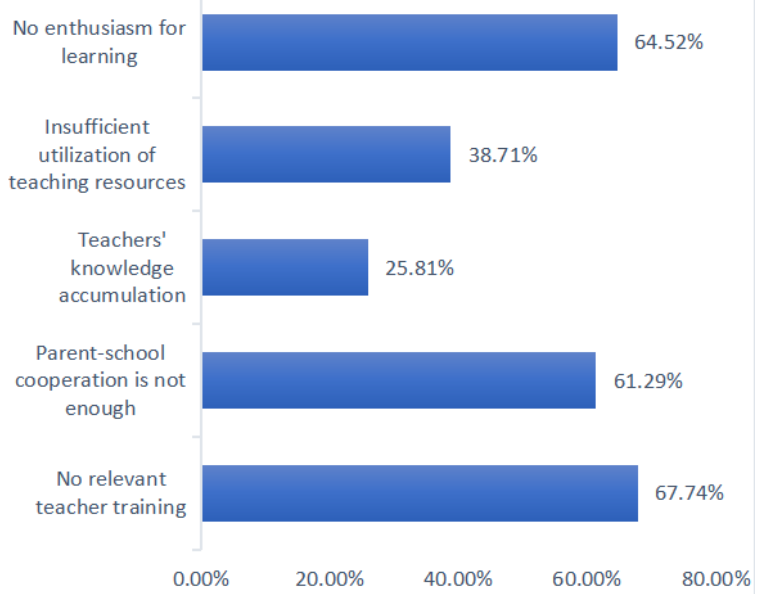

Figure 5 What difficulties do the interviewed teachers think the school has in implementing Chinese traditional culture education

\subsection{Teenagers' attitude towards receiving cultural self-confidence education}

According to understanding of Chinese traditional culture, less than $20 \%$ have a certain in-depth understanding, and most teenagers are at the level of "basic understanding". Thus, a large proportion of teenagers have very limited knowledge of traditional culture. When it comes to Chinese traditional culture, most teenagers think of traditional festivals, folk art, folk art, martial arts, folk music, etc., while less than $10 \%$ mention ancient poetry which occupies an extremely important position in Chinese traditional culture, but most teenagers do not really understand the essence of Chinese poetry culture, especially the rich and heavy cultural charm contained in poetry[22]. The main reason is that the teaching methods are mainly repeated memorization and recitation, which makes students feel boring and rejected. Moreover, the authors and creative backgrounds of ancient poetry are far from our real life, and it is difficult for students to understand the connotation[23].

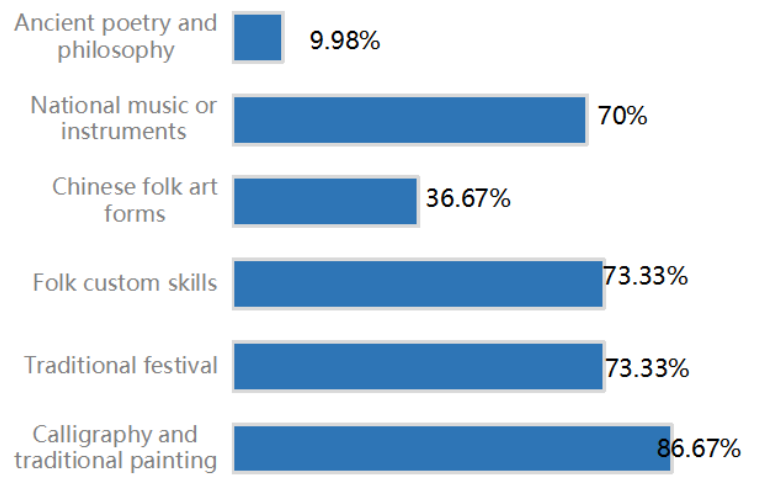

Figure 6 Interviewed students' impression of Chinese traditional culture
From the survey, it is found that although a large proportion of teenagers don't have a deep understanding of their own culture and lack of cultural self-confidence, $60 \%$ of teenagers are "very recognized" by Chinese traditional culture, and more than $85 \%$ of teenagers have a strong will to understand it. They generally agree that "Chinese traditional culture is profound and has a long history, which is worth inheriting and carrying forward". When referring to the future of Chinese traditional culture, most teenagers are optimistic about the future of Chinese traditional culture and have the will to inherit and promote its development.

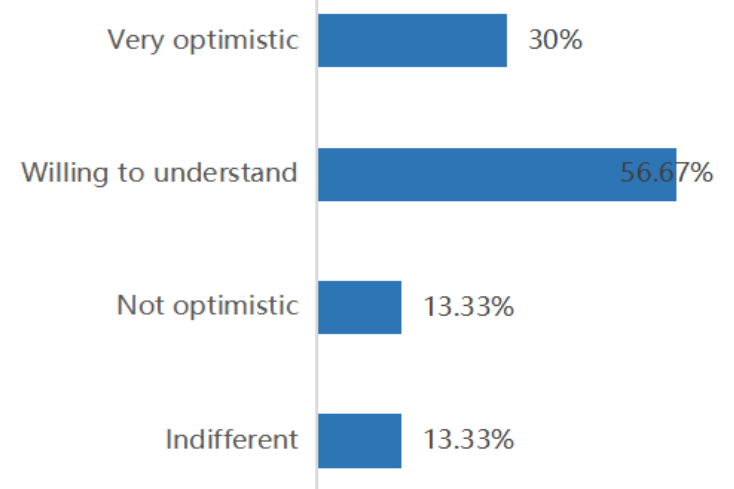

Figure 7 Interviewed students' views on the future development of Chinese traditional culture

More than $90 \%$ of the teenagers who participated in the questionnaire survey believe that Chinese traditional culture plays a significant role in China's future development, with more than $90 \%$ of teenagers expressed their willingness to understand Chinese traditional culture in order to improve their cultural literacy and ideological taste. They want to learn Chinese traditional culture to deepen their understanding of the motherland's history, love their country more, and go abroad with their national pride and cultural confidence in the future.

\section{STRATEGIES FOR PROMOTING CULTURAL SELF-CONFIDENCE EDUCATION OF CHINESE STUDENTS IN INTERNATIONAL SCHOOLS}

Cultural confidence is China's passport to the world. The construction of teenagers' cultural self-confidence is a systematic project, which can start from the joint efforts of mass media, family education and school teaching[24]. Promote their mutual cooperation to ensure the quality of education and consolidate the effect of education. 


\subsection{Enhance the positive influence of mass media on youth's cultural self-confidence education}

Compared with traditional media, the spread of network new media has more effective two-way interaction. For example, the forwarding, commenting and sharing functions of new media such as Weibo and WeChat provide young people space for free expression. Their standpoints and attitudes on cultural self-confidence can be expressed through social media, and the subjective consciousness of young people can be strengthened in the process of participation[25]. In addition, the massive information contained in social media provides rich materials for teenagers to acquire knowledge. Moreover it breaks the time and space boundary of the previous values education, and transmits the cultural self-confidence education to teenagers in a diversified way of information presentation, which provides the possibility to satisfy teenagers' curiosity and thirst for knowledge.

As the media practitioners, should have more such responsibility and consciousness, pay more attention to young people's spiritual level of the trend and development, guidance and intervention of people's moral tendency[26]. Mass media should always make clear their social responsibilities, filter and check the information disseminated by technical methods, give full play to the use of new media in the inheritance of traditional culture, enhance the identification ability of young people, and weaken the impact of unhealthy information on teenagers' values[27], thus further influencing and guiding teenagers to enrich their knowledge structure and improve their comprehensive quality.

\subsection{Strengthen the cooperation of family- school partnerships to promote the cultivation of teenagers' cultural self-confidence consciousness}

Compared with other education, family education should focus on the shaping of non-intellectual personality and the cultivation of national identity[28]. For teenagers, family and school are the two most important environments to cultivate cultural selfconfidence. Family-school co-construction is a key method to promote the development of collaborative education[29]. The main task of the family for the education of teenagers is the foundation for moral and cultural life education. As an important carrier of cultural inheritance, family education is responsible for shaping teenagers' personalities. Parents should take the lead in setting a good example, be the transmitter and guardian of excellent traditional culture, help their children build a cultural system with emotion as the core, and let cultural self-confidence integrate into their spirit[30].

High school students are at a critical developmental stage, which involves becoming mature both physically and mentally, forming life values and worldview. In the process of family-school co-education, schools should fully explore and coordinate various resources to run parent schools well[31], then provide parents with systematic and targeted educational methods to make an effective connection between family education and school education. Furthermore, parents as volunteers need to be guided to make use of their advantages and specialties. it is necessary to invite them to give lectures and share growth experiences for young people, which makes the family and school fully connected and build a new partnership[32], and expands the educational resources of teenagers' cultural self-confidence.

\subsection{Innovate the international school cultivation system and carry out cultural self- confidence education in various forms}

In the process of promoting cultural self-confidence education, international schools should take "Opinions on Implementing the Project of Inheriting and Developing Chinese Excellent Traditional Culture" and "Guiding Outline of Perfecting Chinese Excellent Traditional Culture Education" as guidance, based on the current situation of Chinese youth's cultural selfconfidence education, and set out from the educational goals of cultivating Chinese cultural heritage, enhancing national pride, strengthening cultural self-confidence and being an upright Chinese[33], and combining with the reality of local cultural resources. The historical culture and traditional culture will be developed and experiential, which will provide rich extracurricular activities for young people and make practical cultural learning activities become a supplement to the schoolbased curriculum[34].

During the process of cultural self-confidence education, systematicness and continuity should be especially considered in the curriculum design process. It is necessary to establish the syllabus of cultural selfconfidence education and compile teaching materials so that students can appreciate the style of Chinese culture in different historical periods during their study. Therefore, schools need to break through cognitive limitations and carry out cultural self-confidence education in various forms. It' $\mathrm{s}$ crucial that teachers should have a sense of teaching reflection and clarify the educational significance of traditional culture in order to guide students to establish their own national identity and understanding of cultural self-confidence education. Furthermore, it is particularly important to strengthen the construction of high-quality teachers[35]. Just as the "Outline of the National Medium-and 
Long-Term Education Reform and Development Plan (2010-2020)" puts forward, it is necessary to improve the training system, make practical training plans, and improve teachers' professional level and teaching ability[36].

International schools can cooperate with other countries' schools in- depth and send teachers abroad to visit and exchange, so that teachers can not only come into contact with different teaching concepts through cross-cultural communication but also enrich their cross-cultural experience by traveling, thus improving their own inquiry ability and further broadening their thinking to change the current situation of traditional culture education[37]. Regular teacher training can also provide them new strategies for the secondary development of teaching materials, further improve the optimization of teaching materials and practice teaching students in accordance with their aptitude.

\subsection{Encourage students to participate in extracurricular practice and deepen their self- cultural identity in the learning process}

The construction of cultural self-confidence should not only start with school-based curriculum, but also make teenagers realize that inheriting and carrying forward traditional culture is a necessary condition for them to go to the world. Traditional culture is closely related to western culture, and both of them are indispensable spiritual supplies for the sustainable development of mankind. According to the questionnaire survey, although some teenagers don't know enough about traditional culture and don't have a strong sense of national identity either, they have a positive attitude towards improving their cultural selfconfidence. In fact, teenagers' cultural consciousness is awakening.

Teenagers should give full play to their initiative and take advantage of their holidays to participate in extracurricular activities, such as summer schools, exploration of intangible culture, field trips, international cultural exchange programs, etc. By participating in these extracurricular projects, teenagers not only improve their communication skills and understanding of other countries' cultures, but also enhance their self-identity in multiculturalism, thus forming a correct world outlook and values, and establishing cultural self-confidence in a multicultural environment[38].

\section{CONCLUSION}

With the acceleration of globalization and the increase in the number of international schools, Chinese youth groups are facing the great impact of multiculturalism. It is the primary task to effectively guide and cultivate teenagers' cultural identification ability in the construction of Chinese teenagers' cultural self-confidence[39]. The education of youth's cultural self-confidence is a complex task with the mission of the times, and it is also a long-term process, which must be fully integrated with society, family, and school to form a joint force to support it. The purpose of cultural self-confidence education should be to combine Chinese and foreign excellent educational concepts. Eventually cultivate students to become qualified citizens with both Chinese soul and international vision[40].

\section{REFERENCES}

[1] Jin Huimin. On cultural self-confidence and the new era of globalization. People's forum. academic frontier, doi:10.16619/j.cnki.rmltxsqy.2020.30.034. ]

[2] Zhang Weiwei (2012). The China Wave: Rise of a Civilizational State. World Century Publishing Corporation.

[3] Guo, M. (2018, August). Cultural Confidence and China's International Discourse Power. In 2018 2nd International Conference on Education Science and Economic Management (ICESEM 2018) (pp. 490-495). Atlantis Press.

[4] Teng Jun, Ma Jiansheng, Shi Pei \& Anna. (2019). The modern nature and realization of China's "international education" from a global perspective. Comparative Education Research(12),36-41+50. doi:CNKI:SUN:BJJY.0.2019-12-005.

[5] National policy on international schools in http://www.edu111.cn/info/1063/2358.htm

[6] Interim Administrative Measures of the State Education Commission of the People's Republic of China on Opening Schools for Children of Foreigners

https://mlaw.wkinfo.com.cn/legislation/detail/MTAwM DAxMTQ3ODA\%3D

[7] Xinxueshuo, China's International School Development report (2019), universities consulting analysis, the number of international schools of China. Retrieved from

https://daxueconsulting.com/the-market-ofinternational-school-in-china-a-booming-sector/

[8] Hughes, C. (2020). International Schools and Global Citizenship Education. In Global Citizenship Education (pp. 177-190). Springer, Cham.

[9] Wang Gongmin. Research on Cultivating College Students' Cultural Self-confidence from the Perspective of Community of Human Destiny [J]. Guide to Ideological and Theoretical Education,2019(12):148-151. 
[10] Ou tingyu. the negative influence of the phenomenon of "pan-entertainment" on teenagers' values education and its countermeasures [J]. theoretical guide, ,2020(04):123-128.

[11] Yang Mingquan. (2018). Misunderstanding and localization choice of international curriculum of basic education. Chinese Journal of Education(01),67-71.

doi:CNKI:SUN:ZJYX.0.2018-01-016.

[12] Wang Mingdi \& Zhai Qian. (2020). The Value, Dilemma and Path of Integrating Chinese Excellent Traditional Culture into Teaching. Ethnic Education Research(06),24-30. doi:10.15946/j.cnki.1001-7178.2020.06.005.

[13][29] Nesi, J. (2020). The impact of social media on youth mental health: challenges and opportunities. North Carolina medical journal, 81(2), 116-121.

[14] You Denggui. (2020). Thinking on the development path of traditional cultural programs in the context of cultural self-confidence Taking The Reader as an example. Published in Wide Angle (24),76-78. doi:10.16491/j.cnki.cn451216/g2.2020.24.023.

[15] Wu Xiaoyan \& Tao Fangbiao. (2020). The doubleedged sword effect of the use of digital media on the mental health of children and adolescents. School Health in China (11),1601-1605. doi:10.16835/j.cnki.1000-9817.2020.11.001.

[16] Gao Shuguo. Theoretical Deficiency and Selfconfidence Reconstruction of Family Education Research in China [J]. Education Development Research,2020,40(02):9-17.

[17] $\mathrm{Wu}$ Mowen. (2020). Chinese Fine Traditional Family Style and Moral Education in the New Era. Guide to Ideological and Theoretical Education(11),66-70. doi:10.16580/j.sxlljydk.2020.11.014.

[18] Cui, Y. . (2019). Thought on Traditional Culture and College Chinese Teaching. Proceedings of the 1st International Symposium on Innovation and Education, Law and Social Sciences (IELSS 2019).

[19] Kirkpatrick, R., \& Zang, Y. (2011). The negative influences of exam-oriented education on Chinese high school students: Backwash from classroom to child. Language testing in Asia, 1(3), 1-10.

[20] Yan Wei. (2020). Excavating the elements of educating people in Chinese excellent traditional culture. People's Forum(36),134-136. doi:.
[21] Ismajli, H., \& Imami-Morina, I. (2018). Differentiated Instruction: Understanding and Applying Interactive Strategies to Meet the Needs of All the Students. International Journal of Instruction, 11(3), 207-218.

[22] Yin Qingmin, Zhang Lu\&Du Jianbang. (2020). Research on the value orientation and innovation trend of cultural TV variety shows — Taking the second season of "The Classics of Chanting" as an example. China TV(01),109-112. doi:

[23] Han Bo. (2020). Situational Inspiration Helps Chinese Ancient Poetry Teaching. Chinese Journal of Education(06),105-106. doi:.

[24] Tian, J., \& Han, J. (2021). The Practice and Education Guidance of Youth Cultural SelfConfidence. International Journal of Social Science and Education Research, 4(2), 272-275.

[25] Al-Sabti, D. A., Singh, A. V., \& Jha, S. K. (2017, September). Impact of social media on society in a large and specific to teenagers. In 2017 6th International Conference on Reliability, Infocom Technologies and Optimization (Trends and Future Directions)(ICRITO) (pp. 663-667). IEEE.

[26] Su, X., \& Wu, X. (2017, June). Study on the Spread and Cultural Self-confidence of Chinese Traditional National Culture under the New Media Environment. In 2017 2nd International Conference on Education, Sports, Arts and Management Engineering (ICESAME 2017). Atlantis Press.

[27] Chen, X. (2019). 'Family-culture'and Chinese politeness: An emancipatory pragmatic account. Acta Linguistica Academica, 66(2), 251270.

[28] Wan Ran. (2020). Building an educational community with home-school cooperation. Educational Science Research (10),1. doi:.

[30] He Guimei. (2020). The Value of Traditional Family Training Culture to Contemporary Family Style Construction. School Party Building and Ideological Education (07),94-96. doi:.

[31] (2020). Running a good parent school and promoting family-school cooperation in educating. Research on Education Development (22),41. doi:CNKI:SUN:SHGJ.0.2020-22-008.

[32] Berryhill, B., Morgan, H., Wilson, E., \& Ruggles, H. (2020). The Challenge of Effective Family/School Partnerships: The Middle School Parent Teacher Leadership Academy Pilot Program. Journal of Community Engagement and Scholarship, 13(1), 3. 
[33] [Opinions of the General Office of the CPC Central Committee and the General Office of the State Council on Implementing the Inheritance and Development Project of Chinese Excellent Traditional Culture] 2017

[34] Guo Yuanxiang \& Peng Xuemei. (2020). Infiltrating cultural self-confidence education in primary and secondary school teaching. Educational Research and Experiment (05),1-8. doi:.

[35] Wang Mingdi \& Zhai Qian. (2020). The Value, Dilemma and Path of Integrating Chinese Excellent Traditional Culture into Teaching. Ethnic Education Research (06),24-30. doi:10.15946/j.cnki.1001-7178.2020.06.005.

[36] Cai Wei \& Zhou Lu (2021-01-13). Teacher training promotes the growth of educator-type teachers. China Teachers' Daily, 012. doi:10.28126/n.cnki.ncrjy.2021.000043

[37] Xu Hui \& Chen Qin. (2020). Value Orientation and Practical Path of Global Competency Education from the Perspective of Human Destiny Community. Comparative Education Research (07),3-11. doi:CNKI:SUN:BJJY.0.2020-07-001.

[38] Lin Haikun \& Ha Jianjun. (2021). Multicultural Symbiosis and the Construction of a Community of Human Destiny. Gansu Social Sciences (01),154162. doi:10.15891/j.cnki.cn62-1093/c.2021.01.022.

[39] Yang Xiaohui. (2018). Chinese characteristics and international perspective of youth value education from the perspective of building a community of human destiny. Research on Ideological and Political Education (04),18-21. doi:10.15938/j.cnki.iper.2018.04.004.

[40] Yang Mingquan. (2018). Misunderstanding and localization choice of international curriculum of basic education. Chinese Journal of Education (01),67-71. doi: CNKI:SUN:ZJYX.0.2018-01-016. 